\title{
On Nowadays' Research of the Spread of Chinese as a Foreign Language
}

\author{
Yi Chen \\ Literature and News Media School \\ Chongqing University \\ Chongqing 400030, China \\ E-mail: cdbqcy@126.com
}

\begin{abstract}
China's economic strength in the international community to increase gradually, the Chinese culture in the world gradually is widely disseminating. In today's globalization, cultural soft power has become an important symbol of national power. How to shape the culture of China's soft power is the communication should be concerned about the issue, but also the national strategy on major issues. This article hopes to collect Chinese as a Foreign Language dissemination of academic research and academic monographs. Research, analysis and summary to find out and come to study trends, and based on the use of communications on the basis of the theory of the spread of Chinese law to discuss, In order to provide a big country reference for creating a real culture of Chinese soft power to provide a big country reference
\end{abstract}

Keywords: Chinese as a foreign language, Nowadays

After World War II, countries in the world of rapidly develop political and economic, and promoted all over the range of the exchange, coupled with the growing message traffic facilitate the integration of cultural collision, the world situation is getting smaller and smaller, the global village close to reality. After the founding of New China, especially since the Third Plenary Session of the 11th, the cause of China's opening to the outside world to flourish, more and more foreigners come to China, the implementation of China's reform and opening-up also out of the world. China in particular, after nearly 30 years of reform and opening up, China's rapid economic development, China has become the world's most promising development in power. The Chinese language has increasingly become a major world language. Chinese foreign language study is in the middle of the spread on the Chinese as a Foreign Language Communication, the outcome of the analysis will be conducive to China's soft power to improve. Although the study of Chinese as a foreign language starting late, but contents of the study is diverse, covering a very wide scope of the research. Through the collection of literature, summed up, and its research is in the following areas:

\section{Grammar teaching materials and teaching research}

1980s, the dissemination of Chinese was care about in a wide range. Chinese Academy of Social Sciences and Chinese Language Institute set up the Institute of Applied Linguistics also was the founder of the "Applied Linguistics" magazine, in 1993, held its third seminar on modern Chinese grammar of the Chinese grammar and applied Research is the central issue, More in-depth study of Chinese as a Foreign Language Teaching is grammar problems. In recent years, achievements of Chinese as a Foreign Language Study scattered "in the world of teaching Chinese as a Foreign Language" and "Language Teaching and Research", "overseas Chinese education", "Journal of Chinese language education", "Journal of Yunnan Normal University," and other publications. The main authors contain Zhao Jinming, Hu Ming, Li Quan, Li Chung-ho, Yang Defeng, Lv Wenhua, Ma Jianfei. In the study of grammar textbooks, the most eye-catching one of the areas should be accustomed to talking about "teaching Chinese as a Foreign Language." In the past 20 years, the growing ranks of the field to discuss the issue more and more in-depth. There are the publication of academic works and a large number of Chinese teaching materials and related papers. "Modern Chinese 800 words" (Lu 1980) is an example of Chinese grammar book describes one. It is a research body, but its teaching and learning Chinese as a Foreign Language, also has important practical value. The bulk of the research results for teaching and learning, which is the body but no body. This relationship is like a theory of teaching grammar and syntax of the relationship can not be completely separated. As we have pointed out, Yuen Ren Chao (1980) "in Chinese grammar" is teaching and writing, but it is an important theory of grammar books. That is why, perhaps, in the traditional Chinese science, research and non-body research body you always have me and I'm in you. Many linguists study is the body's master, is also an active participant in applied research. Yuen Ren Chao, Lu, Zhu Dexi and so on, all of the body 
language school has made tremendous contributions, but also all concerned about the language of social applications, including planning and language teaching. For example, Lu bisong (1983), Hang Shi (1995), Zhao Jinming (2001), Zhang Dexin (2000, 2001), such as language teaching methods in the study, "Chinese linguistics and teaching Chinese as a Foreign Language" (2002 Kai), "foreign language teaching In the theory and method "(2004 Chapter Huang Yan Liu)," Teaching Chinese as a Foreign Language "(2004, Wu Yong-yi) can be described as classic. "Chinese as a second language teaching materials development in the form of three" (with Cheng Wen 2004) a more detailed study of the "Chinese fan palm beads timely" since the Chinese as a second language teaching materials, they will be divided into three patterns: Word-centered teaching to the text-centered teaching materials and the structure of the language-centered. It is these step-by-step in-depth discussions so that we continue to think, continue to deepen the understanding of the methods in all made important contributions.

\section{The dissemination of Chinese as a foreign language strategy}

\section{1 large spread strategy}

"The application of modern Chinese language teaching, science and technology and the development of three-dimensional" (Pan guoying )(1972). "Long-range development of teaching Chinese as a Foreign Language" (Teng Qingf), "Teaching Chinese as a foreign language and cultural conflict" (Yao Junling), "in the Context of Globalization of Chinese literature with the fuzzy the boundaries of re-writing history" (Wang Ning), "the global economy And the internationalization of education "(LI Wen-juan), and so on, about economic globalization, China's accession to the WTO, the inevitable education with international practice and opening the education market is bound to rise to the concept of further liberation of the Chinese education will face new development space. The competition Look for opportunities to actively explore the international market in the developing deal with the challenges. We must learn to use international rules, the use of the internationalization of education and opening of the original tap a variety of educational resources, the activation mechanism for education, training and application of international human resources, and actively develop domestic and international markets, with a pragmatic attitude to promote the internationalization of education in China To the development of deep-seated. "On Globalization in the context of Chinese language education policies and the right to speak", "Ball or earth: the dissemination of the reality of China's path to choose" (Guo Henan). "The era of globalization and its significance to the dissemination of Chinese language means" (Gao xiaoyan) in his article, such as analysis of the spread of Chinese language is not just a simple act of proliferation, but also analyzes the significance of the spread of Chinese language, Chinese language to explore the spread via. "Chinese strategy of the State" (Zhang Yi), "Chinese language teaching to promote the globalization " (Wang Jiping) in the paper he pointed out that in the current market demand for Teaching Chinese as a Foreign Language, it is "high season", but we have to find out "weaknesses" at our own Chinese as a Foreign Language .

So that the Chinese language teaching, whether at home or abroad, in order to be able to truly welcome scholars, and the real globalization to promote Chinese language teaching. Thus rely on the national, economic services, and carry forward the tradition of promoting the Chinese language. "Strengthening the international language to promote the dissemination of diverse cultures and common development," Zhang Xinsheng said: We should have Chinese as a foreign language on China's soft power building an important position from the perspective of globalization in the economic, political, cultural, educational and other aspects of a major strategy .The purpose is to promote diversity in the context of globalization of culture and common development. "Teaching Chinese as a Foreign Language remodeling soft power" (Wu Li) in the paper pointed out that the Chinese language and culture and should be economic development, not only to make a "big international circle" concept for the modernization drive for a favorable international environment, and More importantly, the need to implement to promote the dissemination and development strategies can more successfully participate in international competition in the language and culture, develop export-oriented language and culture. "Cross-cultural context to explain the vision of dialogue and integration" (2004 Luling editor-in-chief) mentioned that the language and culture is a kind of convergence and integration of teaching is to build contacts and interaction main way.

\subsection{Chinese as a foreign language talent-building strategy}

"What's the need to disseminate what kind of talent" in the article, Yu Yang pointed out: Today's society is information-based high-speed operation of the society. I try to be grouped into two major parts: school-educated population and quality of technical quality. Science literacy skills and knowledge learned. This was followed by the master of multimedia network technology. The third is the ability of skilled about news. "Contemporary China's publisher and the pursuit of a dream" (Huang Yi), said: At present, although the publishing industry has also opened to the people of the background of overseas, even in the selection of overseas grew up with the advantages of bilingual professionals, with the pursuit which introduce to the Foreign readers a true contemporary China's, then our ideals will be realized one day. In these paper "Chinese as a foreign language professionals to deal with the problem and building measures" Lu Hua and Lee Yecai point out: the world, "Chinese fever" highlights "Shortage of teachers" of the Chinese as a Foreign Language there is an urgent need to strengthen the building of professional Chinese as a Foreign Language, 
training Chinese as a foreign language's teacher. "The Chinese international media: Problems and Solutions" Chung Mong-juan Claim on the world's serious shortage of Chinese teachers, strengthening disciplines at the same time pay attention to the Chinese as a foreign language teacher training envisaged. In "The rise of teaching Chinese as a Foreign Language and Chinese output," make recommendations: the teachers, teaching materials, media, education abroad, and student recruitment efforts.

\subsection{Foreign media strategy}

"Power of information - news media and national development" (Sun juncheng, 2006) in his book Liang Heng said in the preface, the book "in the dissemination of information on how to participate in the cause of national development strategies of the issues discussed." Mentioned it is the original insights in using the media to increase the soft power, in particular in information power, media power, industry power, culture power. "On China's copyright trade of books for the first time surplus "under the analysis of the full text of the publication of the reasons for success, put forward "China's Book Program" to increase investment, the charge of translation quality characteristics by constructing and go " going out "strategy, the publishing industry to have a more positive attitude. "On Globalization and the mass media, the conflict, Interactive" (2002 Tsinghua University Press, Yin Hong Li Bin ) In the book, "The proliferation of Internet in China," Jin jianbin put forward the proliferation of the Internet in China is of special significance This is also the dissemination of Chinese as a foreign language the most important aspect.

\section{The dissemination of historic Chinese as a foreign language study}

"About the dissemination of the Tang Dynasty's" the article Details of the Chinese language in Japan, South Korea's religious and cultural history it is a promotion in research experience. Mr. Dong Ming's "Ancient Chinese History of Chinese foreign dissemination" (Encyclopedia of China Publishing House, 2002), in this area it is a ground-breaking works. Dong consider Ancient Chinese and words as theme, Chinese dynastic history as sequence, countries and regions accept Chinese characters as the main subjects, that is, 'Chinese cultural circle' as the main study subjects, and the peri-ring, involving the South Asian region, Southeast Asia, Central Asia, West Asia, Europe, religious groups. "hundreds of thousands of lengthy character, clearly reveals the different historical periods of Chinese characters in the above-mentioned countries and regions and related religious groups in the dissemination of the case, including the dissemination of the main body of the object, scope, content That way, means, methods, depth, as well as the results of the achievements, the impact of the experiences and lessons should be learned and so on. As a system of ancient Chinese characters on our country to spread the history of a monograph, is great, covers a wide range, could be described as a unified scientific and academic, information and readability of both works. "50 years of teaching Chinese as a Foreign Language - Looking back at the turn of the century, and thinking," recalled the development of teaching Chinese as a foreign language course. Wang Jiang referred to foreign students studying in the development of Chinese language teaching has been 53 years since the "Teaching Chinese as a Foreign Language", the name of the subject from 1983 has been raised so far for more than 20 years. In the meantime Chinese the international situation and subjects China's economy and society have changed dramatically, China teaching has developed into an international Chinese teaching. In the globalization of the world economy to strengthen gradually today, We believe we have to take a look Teaching Chinese as a Foreign Language ups and downs in the past and ponder over the new international situation in the global Chinese as a second language teaching position of the subject and looking forward to the global Chinese as a second language teaching. "The domestic Chinese as a Second Language Acquisition 20" (Shi Jia-Wei, 2006) summed up the system to disseminate Chinese as a Foreign Language Research and Put people to build their own system of research ideas

\section{On the Chinese as a foreign language communication and culture comparative study}

A language or cultural characteristics is more clearly in contrast. This area is characterized by comparing applications to solve problems. People thought that students learn a second language the most difficult to place a second language and mother tongue is a greater difference between the local. It is now also recognize that students learn the difficulties lie in two languages is not always the difference, and the two languages are often similar, or specious. Language itself is not only a cultural phenomenon; it is the carrier of culture and information. A load of different languages grow up with different social, geographical, historical and cultural formation. It found that on many occasions the communication is not a misunderstanding of language but because of the culture. As a result, Chinese cultural content in teaching and $t$ cross-cultural communication, have been the focus of discussion in this area. "Chinese cultural features and significance of cultural transmission" (Liang-hua), "Globalization of the local culture" (Li Qingxia) from the perspective of globalization and localization analysis of the cultural context of the emergence of the phenomenon, pointing out the limitations of local culture Globalization and its impact on the counter to the overall interests of the Earth's core, all of the different local culture of interdependence is an irreversible trend. Therefore, Culture can not be divorced from the practice of local culture and globalization alone, I believe only in the culture of globalization it can be completed

In short, the spread of Chinese as a foreign language, whether foreign or domestic, are not new things, but it is a thing of the rise, it is difficult to make an "either-or" experience and defined. In Chinese as a Foreign Language 
Communication Research found that Experts more care in Chinese as a Foreign Language teaching and practice of teaching materials and methods of cultural transmission and dissemination of the development trend of Chinese as a foreign language study, the little in Chinese as a Foreign Language Communication in the basic theory of Chinese as a foreign language in the dissemination of practice.

Whether we can apply of the basic theory of communication, from the dissemination of the basic elements of the Chinese language, history, through the analysis of the spread of Chinese as a foreign language so that to identify the basic law, to reveal the significance of the dissemination of Chinese as a Foreign Language, so that to spread Chinese as a Foreign Language in the Context of Globalization and How to deal with practical methods and strategies, is an important state affairs.

\section{References}

Amand, Matra. (2005). World Communication and cultural hegemony and strategic thinking of the history of the spread. Translation Publishing House.

Chen Xiaohua. (2007). On the globalization of Chinese language education under the conditions of the cultural heritage. Education Exploring.

Cheng Ming. (2003). Maslow philosophy. Beijing Jiuzhou Publishing House.

Dai Lu. (2001). On the Thought of a culture globalization. China Youth Daily,12(10).

Guo Bonan. (2007). On cross-cultural dissemination. Foreign Mass.

Guo Henan. (2007). Choice of Reality Path for China Overseas Transmission. News knowledge.

Guo xi. (2004). Chinese as a foreign language school. Said a little. To learn Chinese,(4).

Han Ran. (2007). Cross-cultural exchanges between the teaching of Chinese language and measures the impact of Language and Translation. Chinese Language.

Han Yu. (2007). Letter to speed up the world is a big thing - the building of overseas Confucius Institute by leaps and bounds. China Education Review.

Hong Qingiiao. (2005). Teaching Chinese as a foreign language in the ascendant of Chinese exports. Ningbo Institute of Education Journal,(3).

Huang Jinzhang. (2004). Chinese as a foreign language for teaching theories and methods. Beijing University Press.

Li Kai. (2002). Chinese linguistics and Chinese as a Foreign Language Teaching. China Social Science Publishing House.

$\mathrm{Lu}$ Hua and Li Yecai. (2007). Chinese as a foreign language and professional building measures Hengshui University Journal,(3).

Lu Ling. (2004). Vision integration - cross-cultural dialogue and explain the context. Social sciences Press.

Nick, Stevenson. (2001). Awareness of media culture. Business Press.

Qian Xujing. (1999). Foreign students learning Chinese at the time of anxiety - China Institute of Teaching Chinese as a Foreign Language in the sixth academic research papers. Beijing: Chinese Teaching Press.

Sheng Wenjie. (2007). How to meet the Spirit of Chinese. Business News.

Shi Jiawei. (2006). Chinese domestic Second Language Acquisition Research in 20 years. Chinese Teaching and Research.

Sun Jucheng. (2006). Information - Communication and Public Information of the State Development. People's Publishing House.

Wang Jiping. (2006). To promote the globalization of Chinese language teaching. Yunnan Normal University Journal.(Chinese as a Foreign Language Teaching and Research Edition).

Xhen Xuelian and Liang Yibin. (2007). Chinese teaching heat - Overseas opportunity to the publication of teaching materials. China Press and Publication.

Yin Hong and Li Bin. (2002). Globalization and conflict in the mass media integration. Tsinghua University Press.

Zang Julin. (2006). Possession of a -lin go out the pace of new projects. Chinese Journal of Radio and Television.

Zhang Wenjie. (2006). Domestic dissemination of the status quo of teaching Chinese as a Foreign Language Study - A sample based on Huhan International Institute of Education. Young Reporter,(22).

Zhang Xiping and Liu Ruomei. (2006). The promotion of policies, and the Chinese foreign dissemination of Applied Linguistics. Foreign language study. 
Zhang Yi. (2005). National Arts of Chinese strategy. Hunan Normal University Social Science Journal,7(4).

Zhang Zhizhou. China opportunity. Chinese heat behind the World Knowledge,(33).

ZhaoQizheng. (2006). Chinese culture spread outside the ground while reserving differences. People Network.

Zheng Mengjuan. (2006). Chinese international spread: Problems and Solutions. Jianghan University Journal,(6). 